\title{
PHYSICAL AND MECHANICAL PROPERTIES OF SOME PLASTER MORTARS WITH OXIDE WASTES
}

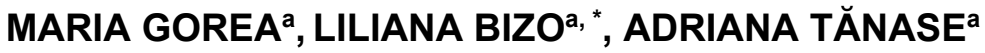

\begin{abstract}
The present study evaluates the characteristics and performances of plaster mortars for construction, with the addition of oxide waste resulted from the filling of metal statues. Several plaster mortars using 0 $\%, 5 \%, 10 \%, 15 \%$ and $20 \%$ wt. of waste in composition were prepared in the laboratory and the physical and mechanical characteristics were determined. The waste oxide composition is mainly formed of $61.26 \% \mathrm{SiO}_{2}$, $11.20 \% \mathrm{Al}_{2} \mathrm{O}_{3}$ and $23.50 \% \mathrm{CaSO}_{4}$. The consistency water is about $75 \%$ for mortars without waste. With increasing the waste content in the mortar composition, the amount of water decreases at about $50 \%$. It was also determined the setting time for all plaster mortars without any setting time retarder. The initial setting time for the control mortar was 12 minutes and with increasing the waste percentage in the composition, the setting time increased proportionally, reaching 18 minutes for the sample with $20 \%$ wt. waste. The flexural strength of $2.03 \mathrm{~N} / \mathrm{mm}^{2}$ and compressive strength of $10.31 \mathrm{~N} / \mathrm{mm}^{2}$ were obtained for the sample with the highest amount of waste (20\% wt.).
\end{abstract}

Keywords: oxide waste, plaster mortar, mechanical properties

\section{INTRODUCTION}

There is growing concern in the last decades about the large amount of waste generated and the damage that this causes to the planet. At European level, waste management policies aim to reduce the environmental and health impacts of waste and to improve the EU's resource efficiency. The long-term aim of these policies is to reduce the amount of waste generated and when waste generation is unavoidable to promote it as a resource and achieve higher levels of recycling and the safe disposal of waste [1, 2].

Building mortar is a building material formed by mixing cement, fine aggregates, mixtures and water in a suitable proportion, and the use of ceramic

\footnotetext{
a Babeş-Bolyai University, Faculty of Chemistry and Chemical Engineering, 11 Arany Janos str., RO-400028, Cluj-Napoca, Romania

*Corresponding author: Ibizo@chem.ubbcluj.ro
} 
waste in mortar production dates back to the ancient times. The development of suitable repair mortar for historic masonry requires knowledge about chemical and mineralogical composition and information about the mechanical and physical properties of individual structures $[3,4]$. It has recently been suggested that mortars may be characterized by their mineralogical composition and micro structural appearance [5]. Also the understanding of all the physical chemical property is very important for this class of materials [6].

Many studies focusing on the addition of waste in a plaster matrix are found. Moreover, there are many researches about adding different types of wastes to gypsum plaster matrix.

The paper waste generated in the manufacture of paper can be a component of plaster composite material in adequate proportion. The use of paper pulp waste in plaster mortars does not involve any difficulties although it is advisable drying the paper waste before utilization. As such, the mechanical and rheological properties are enhanced and fragmenting the waste ensures a homogeneous mixture [7].

Plaster composites obtained by mixing plaster with different proportions of unburnt rice husk, blast furnace slag, calcium carbonate or poly vinyl alcohol polymer were tested. The study demonstrated that rice husk, polymer and calcium carbonate additions increased while slag decreased normal consistency water, all additives delayed the setting time, increased the apparent porosity and decreased bulk density of their corresponding composites. The compressive strength is not considerately improved, the being recommended for lightweight high-porosity building structures [8].

The mineral wools waste, both rock wool and glass wool, into a plaster matrix could be embedded in the core of plasterboards increasing their flexural strength [9].

The addition of foam ground rubber waste up to $7.5 \%$ in the lightweight plaster composite ensures a good workability, obtaining a homogeneous paste without any segregation. Also ground rubber coming from pipe foam insulation was used for obtaining a new lightweight product for building construction [10].

Saw dust, coconut fibers and tobacco waste fiber incorporated in the plaster mortar composition have improved the thermal property. Diatomaceous earth, fly ash and bottom ash improved the mechanical and thermal properties. In addition, these samples with citric retarder enhanced fire protection [11].

Del Río Merino et al. studied the physical and mechanical properties of a lightened eco-plaster mortar, manufactured with aggregates from ceramic and extruded polystyrene wastes. The mortars with these wastes reduce the water absorption by capillarity and increase the superficial hardness compared with etalon mortar [12].

The mechanical characteristics, the thermal conductivity and the sound absorption capacity of the plaster plates with wood waste (wood shavings and sawdust) were studied by Pedreño-Rojas et al. The greatest 
thermal improvement occurs by adding $20 \%$ of wood shavings in the mortar composition [13].

The use of polymeric wastes as polymer additives in the manufacture of lightweight plasters has been widely studied with a view to improve the thermal behavior of these materials. The properties of plaster mortar and paste rheology containing polyurethane foam and polyamide powder waste are comparable to that of lightweight composite realized with conventional materials [14, 15].

To our knowledge there is no reference about the use of waste resulted from the filling of the metal statues incorporated into a plaster mortar. For this reason our paper aimed to study the effect of waste addition into plaster-based mortar, from point of view of physical and mechanical properties.

\section{RESULTS AND DISCUSSION}

\section{Characterization of raw materials}

\section{Plaster}

The plaster used in the experiments is a commercial modeling plaster, traditionally used in building construction due to its good properties as it provides in fire protection, as thermal isolation and its contribution to equilibrate the humidity in rooms.

\section{Oxide waste}

The oxide waste resulted from thermal treatment at $600^{\circ} \mathrm{C}$ of a mixture of $50 \%$ sand, $25 \%$ fired clay and $25 \%$ gypsum used in the casting process of the art metal statue was introduced as the aggregates in plaster mortars.

Chemical composition of waste

The chemical composition of the oxide waste realized by traditional wet chemistry analyses is presented in Table 1.

Table 1. Chemical composition (wt.\%) of the oxide waste.

\begin{tabular}{|c|c|c|c|c|c|c|c|c|c|}
\hline Oxide & $\mathrm{SiO}_{2}$ & $\mathrm{TiO}_{2}$ & $\mathrm{Al}_{2} \mathrm{O}_{3}$ & $\mathrm{Fe}_{2} \mathrm{O}_{3}$ & $\begin{array}{c}\mathrm{CaO} / \\
\mathrm{CaSO}_{4}\end{array}$ & $\mathrm{MgO}$ & $\mathrm{Na}_{2} \mathrm{O}$ & $\mathrm{K}_{2} \mathrm{O}$ & $\mathrm{LOI}$ \\
\hline $\begin{array}{l}\text { Waste } \\
\text { [wt.\%] }\end{array}$ & 60.24 & 0.82 & 12.44 & 0.49 & 23.30 & 0.36 & 0.28 & 0.72 & 1.35 \\
\hline
\end{tabular}

The oxide waste contains the silicon dioxide and aluminium oxide resulted from thermal treated of sand and fired clay and calcium oxide $\left(\mathrm{CaSO}_{4}\right)$ from gypsum dehydration. The minor oxides are originating from impurities presented in fired clay. 


\section{$X$-ray diffraction}
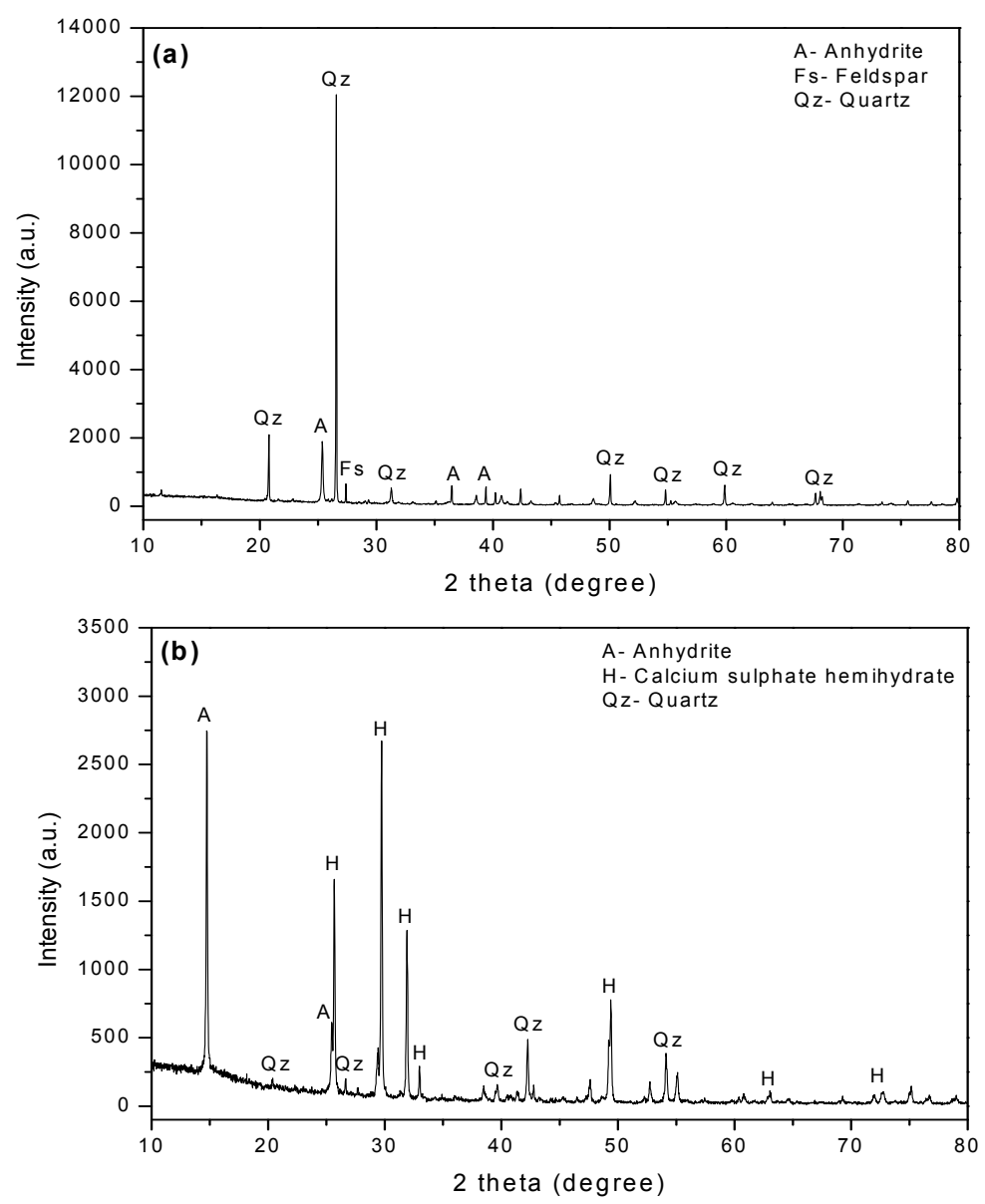

Figure 1. X-ray diffraction pattern of oxide waste (a), plaster (b).

The mineralogical composition, presented in Figure 1(b), of plaster was investigated by $\mathrm{X}$-ray diffraction using a Shimadzu 6000 apparatus. The identified compounds are calcium sulphate hemihydrate $\left(\mathrm{CaSO}_{4} \times 0.5 \mathrm{H}_{2} \mathrm{O}\right)$ as a majority, anhydrite $\left(\mathrm{CaSO}_{4}\right)$ low content and small quantities of impurities quartz $\left(\mathrm{SiO}_{2}\right)$. The quartz impurity in plaster does not influence the mortar properties, it acts as a fine aggregate.

In Figure 1(a) the X-ray diffraction pattern of oxide waste used in experiments are illustrated. The main mineralogical compounds evidenced are quartz $\left(\mathrm{SiO}_{2}\right)$, feldspar, anhydrite $\left(\mathrm{CaSO}_{4}\right)$. 


\section{Grain size distribution}

For physical characterization of components of the oxide waste plaster mortars, their grain size distributions were performed by a Shimadzu laser-diffraction analyzer. Samples were immersed for $15 \mathrm{~s}$ in isopropyl alcohol used as a solvent, with aggregation being reduced using treatment with ultrasounds. Grain size distribution of the plaster used in experiments is represented in Figure 2 (a) and in Figure 2(b) for oxide waste.
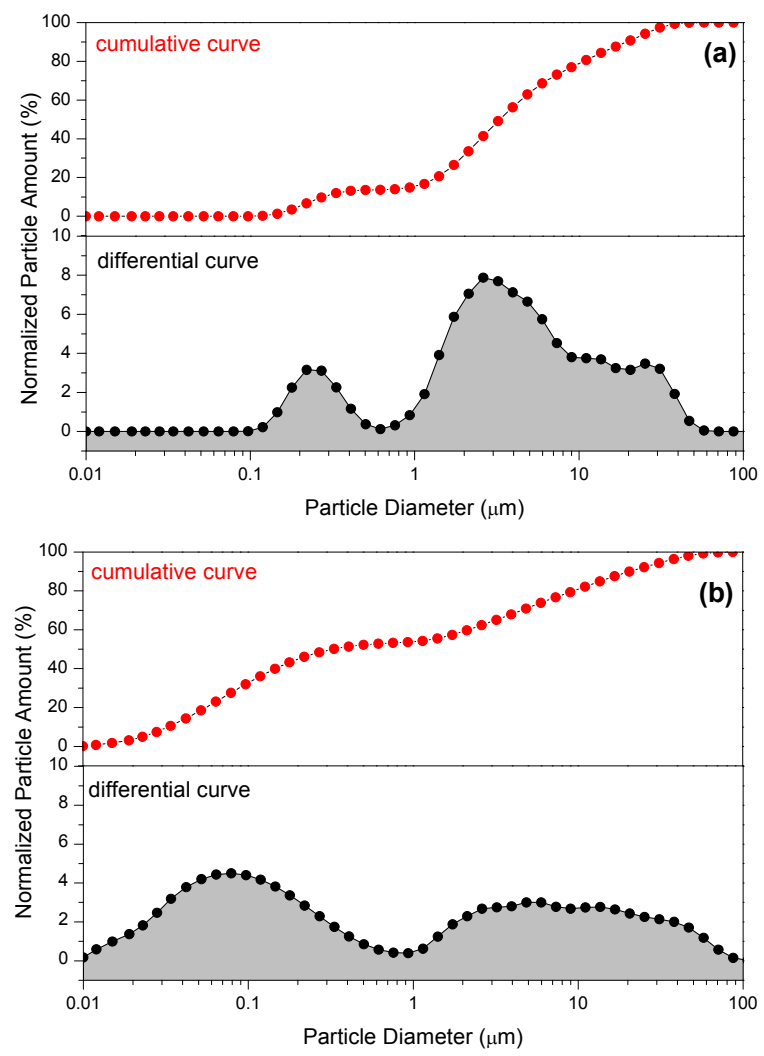

Figure 2. Grain size distribution for plaster (a) and oxide waste (b).

The size of plaster grains is less than 131 microns; $54 \%$ of the grains are less than 1 micron and the smallest value of the plaster grain is $10 \mathrm{~nm}$. In the case of oxide waste, the highest value of grain size is 71 microns, only $14 \%$ of the grains are less than 1 micron and the lowest size is of $97 \mathrm{~nm}$. The size of the plaster grains close the oxide waste and ensure workability and homogeneity of the mixtures. 


\section{Characterization of mortar samples}

Macroscopic aspect

Figure 3 illustrates the aspect of the experimented M5 sample, containing $20 \%$ oxide waste. A homogeneous sample without any segregation of waste is observed. The uniform distribution of oxide waste and smooth surfaces in all studied samples were evidenced.

\section{Consistency water}

Reference plaster paste (without oxide waste) and pastes with different content of waste replacing the plaster were mixing according to the specific standard. After the rest and mixing time has passed the paste is introduced into a cylindrical ring measuring $40 \mathrm{~mm}$ in height and an internal diameter of $30 \mathrm{~mm}$ supported on a glass plate. Subsequently, the mold was removed allowing the paste to spread out. The sample diameter was measured in both directions perpendicular to each other.

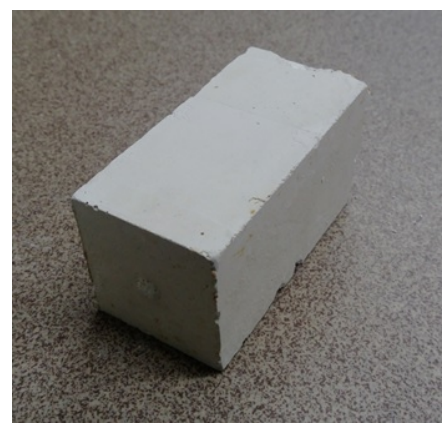

Table 2. Consistency water for studied samples.

\begin{tabular}{|l|c|}
\hline \multicolumn{1}{|c|}{ Sample } & $\begin{array}{c}\text { Consistency } \\
\text { Water [\%] }\end{array}$ \\
\hline Reference sample M1 & 75 \\
$5 \%$ waste sample M2 & 70 \\
$10 \%$ waste sample M3 & 65 \\
$15 \%$ waste sample M4 & 60 \\
$20 \%$ waste sample M5 & 50 \\
\hline
\end{tabular}

Figure 3. Macroscopic aspect of M5 sample.

The normal consistency water (Table 2) of the used plaster was determined to be of $75 \%$ which means that each $100 \mathrm{~g}$ plaster powder mixes with $75 \mathrm{ml}$ water for obtaining of normal consistency paste. The addition of oxide waste decreases the normal consistency water of plaster mortars. Generally, the addition of any additive in plaster mortar involves a decrease of plaster content. Thus the normal consistency water for plaster waste composites is ranged from $70 \%$ to $50 \%$ for samples that contain 5 , 10,15 and $20 \%$ oxide waste. 


\section{Setting Time}

The setting times of the plaster mortars prepared with different quantities of oxide waste are given in Table 3. It can observe that the initial setting time is the same for all samples. So, the additions of oxide waste in mortar composition no influence the initial setting time.

Table 3. Setting times of the different plaster mortars compositions.

\begin{tabular}{|l|c|c|c|c|c|}
\hline Sample/Characteristic & M1 & M2 & M3 & M4 & M5 \\
\hline Initial setting time [min] & 12 & 12 & 12 & 12 & 12 \\
\hline Final setting time [min] & 15 & 16 & 17 & 17 & 18 \\
\hline
\end{tabular}

On the other hand, the final setting times increase by adding the oxide waste. This fact could be explained by the presence of $\mathrm{CaSO}_{4}$ - soluble anhydrite, in the waste and/or in plaster composition which needs a more long time to hydrate comparing with $\mathrm{CaSO}_{4} \times 0.5 \mathrm{H}_{2} \mathrm{O}$ hemihydrate.

Plaster mortars density

In Table 4 are presented the densities obtained for experimented mortars. It is observed that plaster mortar with additions of oxide waste achieves value higher than the reference samples (M1).

Table 4. Densities of different studied plaster mortars compositions.

\begin{tabular}{|l|c|c|c|c|c|}
\hline Sample & $\mathrm{M} 1$ & $\mathrm{M} 2$ & $\mathrm{M} 3$ & $\mathrm{M} 4$ & $\mathrm{M} 5$ \\
\hline Density $\left[\mathrm{g} / \mathrm{cm}^{3}\right]$ & 1.09 & 1.21 & 1.25 & 1.28 & 1.32 \\
\hline
\end{tabular}

The density of mortars with oxide waste is increased because of waste density which is higher than $2 \mathrm{~g} / \mathrm{cm}^{3}$. Therefore, for every $5 \%$ of waste incorporated in the plaster mortar, the density increases with 11, 15, 17 and $21 \%$ compared with reference mortar (M1).

\section{Mechanical Resistance}

\section{Flexural strength}

In Figure 4 are presented the flexural strength for the experimented mortars. The results shows that adding the oxide waste in gypsum plaster matrix improve the flexural strength compared to the reference sample.

Additions of $5 \%$ waste in mortar composition no influence on flexural strength $\left(1.49 \mathrm{~N} / \mathrm{mm}^{2}\right)$. 10 and $15 \%$ waste in experimented composition increase the flexural strength to 1.72 respectively $1.80 \mathrm{~N} / \mathrm{mm}^{2}$. But adding 
up to $20 \%$ waste in the composition can increase the flexural strength up to $35 \%\left(2.03 \mathrm{~N} / \mathrm{mm}^{2}\right)$. These mechanical behaviors of plaster mortars could be explained also through increasing their densities comparing the reference sample (about 11 to $21 \%$ ).

\section{Compressive strength}

The compressive strengths of the studied samples are illustrated in Figure 5.

With the addition of the oxide wastes the compressive strength values increase as the percentage of waste is increased. So, adding the 5 and $10 \%$ waste in mortar composition the compressive strength slightly increases, from $4.72 \mathrm{~N} / \mathrm{mm}^{2}$ to 5.43 respectively $5.51 \mathrm{~N} / \mathrm{mm}^{2}$. When $15 \%$ and $20 \%$ waste are added the compressive strength, values are increased up to $70 \%$ respectively $100 \%$ (from 4.72 to 8.11 respectively $10.31 \mathrm{~N} / \mathrm{mm}^{2}$ ).

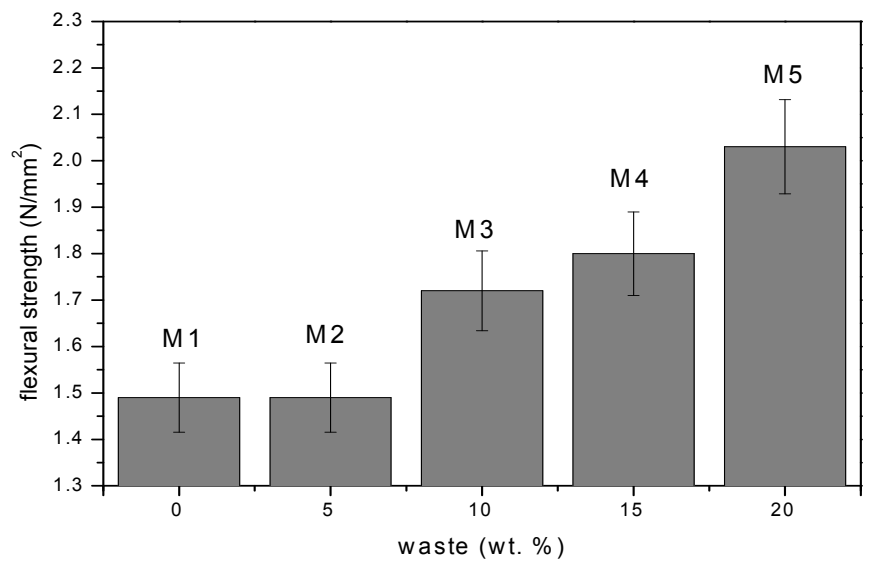

Figure 4. Flexural strength of oxide waste plaster mortar.

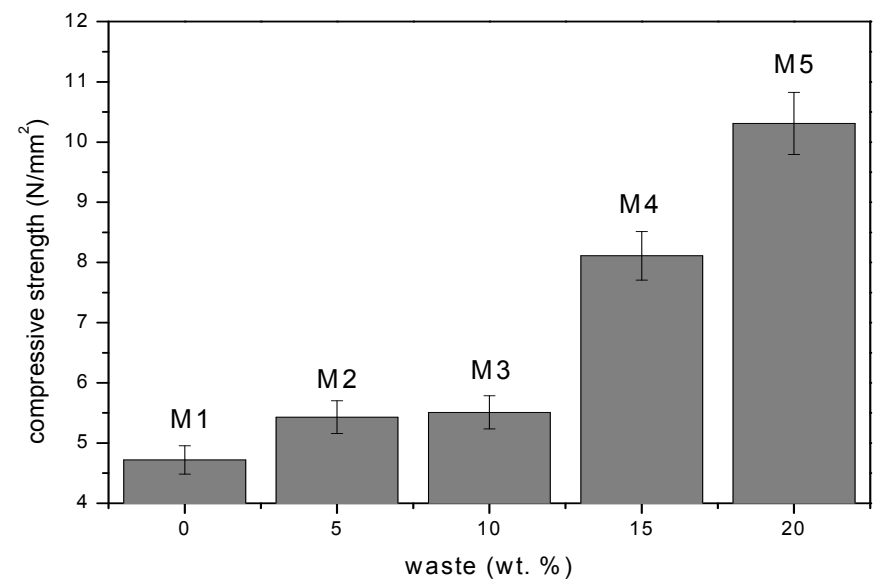

Figure 5. Compressive strength of oxide waste plaster mortar. 


\section{CONCLUSIONS}

The using of oxide waste powder as a recycled and reusable material in various plaster mortars is therefore of great interest in the obtaining of new building materials. This fact would contribute to the reassessment of different waste products that are generated in large amounts.

In this respect, the addition of oxide wastes as a plaster substitute has a good influence on the final plaster mortar properties. The addition of oxide waste decreases the normal consistency water of plaster mortars. The final setting times and densities increase by adding the oxide waste. Adding up to $20 \%$ waste in the composition can increase the flexural strength up to $35 \%\left(2.03 \mathrm{~N} / \mathrm{mm}^{2}\right)$. The compressive strength values are increased up to $70 \%$ respectively $100 \%$ by adding $15 \%$ and $20 \%$ oxide waste in composition (from 4.72 to 8.11 respectively $10.31 \mathrm{~N} / \mathrm{mm}^{2}$ ).

This preliminary study tries to justify the possibility of reusing this type of oxide waste as an alternative raw material in some lightweight building materials.

\section{EXPERIMENTAL SECTION}

\section{Experimented compositions}

\section{Materials}

The experimented plaster mortars are presented in the Table 5. Five blended plaster mortars with different addition of oxide waste were mixed (M1, M2, M3, M4 and M5).

Table 5. The prepared plaster mortar compositions.

\begin{tabular}{|c|c|c|c|c|c|c|}
\hline \multicolumn{2}{|c|}{ Samples code } & M1 & M2 & M3 & M4 & M5 \\
\hline \multirow{2}{*}{ Composition } & Plaster (wt. \%) & 100 & 95 & 90 & 85 & 80 \\
\cline { 2 - 7 } & Waste (wt. \%) & 0 & 5 & 10 & 15 & 20 \\
\hline
\end{tabular}

The procedure for obtaining the pastes consisted of progressive additions of oxide waste powder to the plaster, substituting by weight different proportions of plaster for waste. The dry plaster and waste are mixed until homogenisation, about 20 minute. The consistency water is measured and put in a laboratory vessel. The homogenised mixtures sprinkle gradually for 30 secunds in the water. The resulted paste is mixed for 1 minute and then pours uniformaly in three molds. The samples are kept 2 hours in molds and after hardening they are removed. 


\section{Methods}

Particle size analysis in suspension was performed using Shimadzu SALD7101 micro- and nanoparticle analyzer (Japan). The nanoparticle size analyzer can handle a broad range of measurement objects and purposes. Using this apparatus, serial measurements based on the same measurement principle are possible for particle size varying within a measurement range from $10 \mathrm{~nm}$ to $300 \mu \mathrm{m}$.

Crystalline phases were determined by X-ray diffractometer (XRD, Shimadzu 6000) using $\mathrm{Cu}$-Ka radiation $(\lambda=1.5406 \AA)$ equipped with $\mathrm{Ni}$-filter in a $2 \theta$ range of $10^{\circ}-80^{\circ}$.

The mechanical characteristics (compressive and flexural strength) are investigated on hydraulic press CONTROLS 50-C66V2 in accordance with Romanian standard SR EN 196-1.

\section{REFERENCES}

1. http://ec.europa.eu/environment/waste/legislation/index.htm, EU Waste Legislation.

2. http://ec.europa.eu/environment/waste/target_review.htm, Review of Waste Policy and Legislation.

3. M. Singh, S. Waghmare, S. Vinodh Kumar, Journal of Archaeological Science, 2014, 42, 430.

4. J. Schafer, H. K. Hilsdorf, "Ancient and new lime, mortars: the correlation between their composition and properties", in: Theil, M.J. (Ed.), Proceedings of the Conservation of Stone and Other Materials, vol. 2, E \& FN Spon, Paris, 1993, 605.

5. A. E. Charola, M. Dupas, R.P. Sheryll, G.C. Freund, "Scientific methodologies applied in works of arts", Proceeding of the $1^{\text {st }}$ International Symposium, Firenze, 1984, 28.

6. J. E. Adam, W. A., Kneller, "Thermal analysis of medieval mortars from Gothic Cathedrals of France", in: Marinas, Koukis (Eds.), Engineering Geology of Ancient Works, Monuments and Historic Sites. Balkema, Rotterdam, 1988, 1019.

7. L. Agullo, A. Aguado, T. Garcia, Building and Environment, 2006, 41, 821.

8. A. A. Khalil, A. Tawfik, A. A. Hegazy, M. F. El-Shahatet, Construction and Building Materials, 2014, 68, 580.

9. S. Romaniega Piñeiro, M. del Río Merino, C. Pérez García, Advances in Materials Science and Engineering, 2015, article ID 854192.

10. A. Jiménez Rivero, A. de Guzmán Báez, J. García Navarro, Construction and Building Materials, 2014, 55, 146.

11. P. Chindaprasirt, K. Boonserm, T. Chairuangsri, W. Vichit-Vadakan, T. Eaimsin, T. Sato, K. Pimraksa, Construction and Building Materials, 2011, 25, 3193.

12. M. del Río Merino, J. Santa Cruz Astorqui, P. Villoria Sáez, R. Santos Jiménez, M. González Cortina, Construction and Building Materials, 2018, 158, 649.

13. M. A. Pedreño-Rojas, M. J. Morales-Conde, F. Pérez-Gálvez, C. RodríguezLiñán, Journal of Cleaner Production, 2017, 166, 690.

14. S. Gutiérrez-González, J. Gadea, A. Rodríguez, C. Junco, V. Calderón, Construction and Building Materials, 2012, 28, 653.

15. S. Gutiérrez-González, M.M. Alonso, J. Gadea, A. Rodríguez, V. Calderón, Construction and Building Materials, 2013, 38, 407. 